\title{
Reformulação do Sistema Internacional de Medidas: demandas pedagógicas
}

\author{
Xavier, L. A. ${ }^{1^{*}}$; Rodrigues, C. F. ; Ribeiro, R. B. G. ${ }^{1,2}$; Rabelo, U. A. ${ }^{1}$ Fardim, S. V. S. ${ }^{3}$; \\ 1 Escola Professora Filomena Quitiba, Piúma, ES, Brasil. \\ 2 Programa de Pós-Graduação em Educação em Ciências e Matemática (EDUCIMAT), Instituto Federal do Espírito \\ Santo (IFES), Vitória, ES, Brasil. \\ 3 Programa de Pós-Graduação em Ciência, Tecnologia e Educação (FVC), São Mateus, ES, Brasil \\ *e-mail: lucas.perobas@gmail.com
}

\begin{abstract}
Resumo
O presente artigo tem como objetivo trazer uma discussão da importância do Sistema Internacional de Medidas, principalmente a reformulação ocorrida em 2019 para os alunos do ensino médio. O cotidiano estar repleto de tecnologias e elas para serem compreendidas é necessário o entendimento dos conceitos envolvidos em cada uma das sete unidades base, mesmo que nossos alunos não sejam pesquisadores no futuro. O entendimento passa pelo olhar do abandono do sistema que considerava objetos físicos e adoção das constantes da ciência/física que não altera com o passar do tempo. Os procedimentos se estrutura na pesquisa-ação com alunos das turmas do ensino médio da escola estadual do ensino fundamental e médio professora Filomena Quitiba com envolvimento de 10 turmas. Em cada turma houve a formação de 7 grupos, cada um com umas das respectivas grandezas do SI, comprimento, tempo, massa, corrente elétrica, temperatura termodinâmica, quantidade de matéria e intensidade luminosa. $\mathrm{O}$ trabalhado apresentado pelos alunos em forma de seminário foi relevante ao retratar o SI, que se baseia em sete grandezas físicas independentes, denominadas unidades de base. Foi desafiador para uma parcela dos grupos, pois algumas definições exigiam conhecimento de física moderna, apontando que a rota adotada mostra o caminho a ser trilhado em prol de uma educação condizente com o século XXI.
\end{abstract}

Palavras chave: Formação continuada, metodologia, Ensino de Física, Sistema de Unidades.

\begin{abstract}
This article aims to bring a discussion of the importance of the International Measurement System, especially the reformulation that took place in 2019 for high school students. The daily life is full of technologies and to be understood it is necessary to understand the concepts involved in each of the seven base units, even if our students are not researchers in the future. Understanding involves looking at the abandonment of the system that considered physical objects and adopting the constants of science / physics that do not change over time. The procedures are structured in action research with high school students from the state elementary and high school teacher Filomena Quitiba with the involvement of 10 classes. In each class, 7 groups were formed, each with one of the respective magnitudes of the SI, length, time, mass, electric current, thermodynamic temperature, amount of matter and luminous intensity. The work presented by the students in the form of a seminar was relevant in portraying the SI, which is based on seven independent physical quantities, called base units. It was challenging for a portion of the groups, as some definitions required knowledge of modern physics, pointing out that the route adopted shows the path to be followed in favor of an education consistent with the 21 st century.
\end{abstract}

Keywords: Continuing education, methodology, Physics teaching, Units System. 


\section{Blucher Proceedings \\ XI Encontro Científico de Física Aplicada}

\section{Introdução}

$\mathrm{Na}$ educação básica ensinamos que, em diferentes operações, que envolvem pesos e medidas, é imprescindível realizar a conversão para um sistema padrão, sem essa percepção, erros e confusão se instalam. Nessa perspectiva, a agência espacial americana (NASA), admitiu em 1999 que, um erro primário causou a perda da sonda Mars Climate Orbiter, projetada para estudar o planeta Marte, pois utilizaram dois sistemas, o Sistema Métrico Decimal e o Sistema Imperial Britânico. Ao aproximar de Marte alimentaram a nave com informações em metros, quilogramas, pés e libras. Precisamos refletir, juntamente com os alunos, sobre a importância da adoção de um sistema padronizado como o Sistema Internacional de Medidas (SI) e aprender a ler a reformulação ocorrida em 2019. Assim, coaduna com a fala [1] ao citar o pensamento de Paulo Freire:

\begin{abstract}
Afirmava que a leitura do mundo precede a leitura da palavra. E mais, que o verdadeiro sentido da leitura é a possibilidade que ela oferece ao aprendiz de reler o seu mundo a partir da superação daquela 'leitura' anterior ingênua, adquirindo uma criticidade tal que permita-o impetrar mudanças radicais em sua realidade (HENNING, 2005, p. 451).
\end{abstract}

Aprender criticamente é possível e faz parte da tarefa docente não apenas ensinar conteúdos, mas também ensinar a pensar certo, enfatizando a aprendizagem do conteúdo já existente e o trabalho na produção do conhecimento ainda não existente [2]. Dessa forma, criar um ser capaz de compreender sua tarefa no ambiente e na sociedade faz parte da tarefa docente.

O SI é um sistema coerente de unidades, adotado e recomendado pela Conferência Geral de Pesos e Medidas (CGPM). A adoção do SI no Brasil se deu por meio do Decreto n. ${ }^{\circ}$ 52.243, de 30/8/1963, mais tarde substituído pelo Decreto n. 63.323 , de 12/9/1968 [3]. A atividade proposta aos alunos se justifica, pois, a escola ensina que para qualquer operação que envolva operações diferentes de pesos e medidas é necessário fazer a conversão para um único sistema de unidades.

Todos os cidadãos devem ter certas aptidões, uma delas é o domínio do SI para compreender a linguagem científica. Esse pensamento se justifica pela possibilidade de que, um conhecimento mais amplo proporciona um prazer adicional na descoberta do mundo que nos rodeia. Portanto, o trabalho tem como objetivo geral, promover uma reflexão sobre as 7 unidades do SI enfrentadas pelo aluno, mais especificamente no que diz respeito à utilização. Nossos objetivos específicos são: a) compreender a importância do cuidado e tratamento adequado das unidades do SI e b) refletir sobre as mudanças ocorridas em 2019 na redefinição do quadro de unidades do SI e que possam impactar no futuro.

A reformulação é fundamental ao fazer ciência avançada, por outro lado, será importante refletir sobre essas unidades em sala de aula, mesmo que a maioria de nossos alunos talvez não sejam pesquisadores no futuro.

Dentre os sistemas de unidades existentes, o SI é o sistema de medidas mais utilizado. Para cada unidade existe uma grandeza, cujo objetivo é uniformizar as medições. O SI foi criado em 1960, é utilizado em quase todo o mundo, explicita que [3]:

Em 1960, a $11^{\circ}$ Conferência Geral de Pesos e
Medidas - CGPM instituiu o Sistema
Internacional de Unidades - SI, sistema esse,
que estabeleceu a cada grandeza somente
uma unidade. Na $14^{\circ}$ CGPM que ocorreu em
1971, foram selecionadas as unidades de base
do SI, que são: metro, quilograma, segundo,
ampère, kelvin, mol e candela, que
correspondem às grandezas fundamentais:
comprimento, massa, tempo, intensidade de
corrente elétrica, temperatura, quantidade de
matéria e intensidade luminosa. Nessa mesma
conferência foram estabelecidos também, seus
símbolos, unidades derivadas, unidades
suplementares e prefixos (INMETRO, 2012) A adoção do sistema métrico de unidades seguindo um padrão internacional foi fundamental para alavancar a qualidade da ciência, ilustrado na Figura 1. 




Em 2019 o sistema passou por uma reformulação, conforme figura 2 .

Figura 2: Novo SI

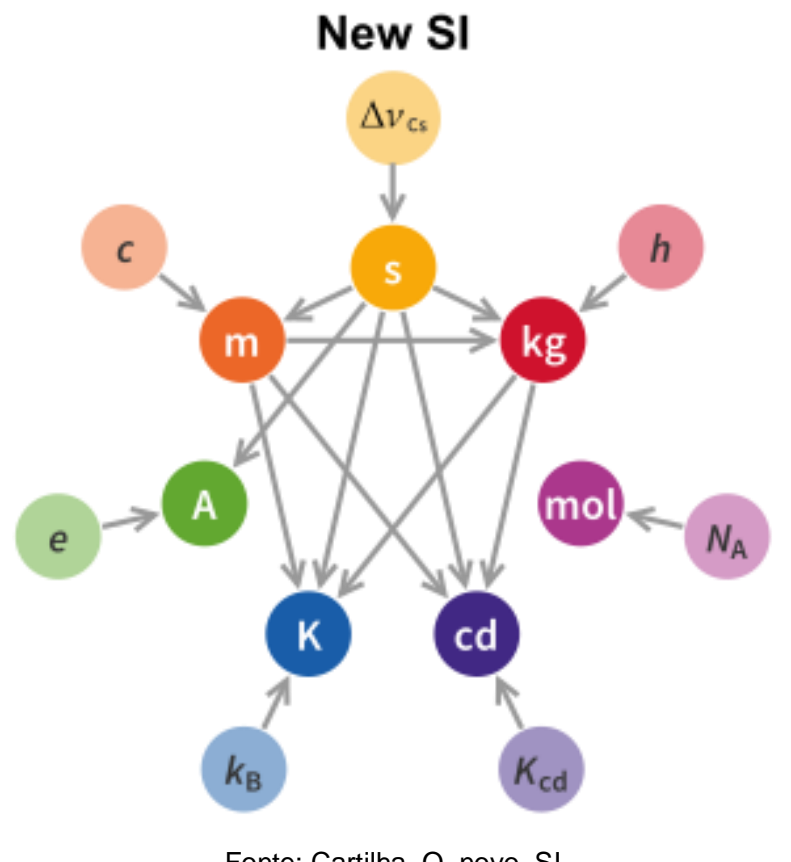

Fonte: Cartilha_O_novo_SI

O método foi útil ao seguir padrões e definições de objetos físicos, mas com a crescente necessidade de maior precisão nas medidas, principalmente com física moderna, novos rigores foram adotados, abolindo objetos físicos e adotando definições de valores que não se alteram com o tempo. Portanto, o olhar foi em direção às constantes fundamentais da ciência/física. O tempo, por exemplo, tem o segundo como unidade, definido classicamente em termos rotação e translação da Terra, atualmente é definido como frequência da radiação eletromagnética necessária para efetuar eficientemente a transição entre os estados hiperfinos do átomo de Césio-133 [4]. Esse átomo não muda com o tempo e sua transição entre seus estados eletrônicos é uma constante, que tem grande utilidade em relógios atômicos. Na reforma do SI ocorrida em 2019, sofreram mudanças as seguintes unidades: o quilograma passou adotar a constante de Planck $h$, o ampèrie, a constante da carga elétrica c, o kelvin a constante de Boltzman k e o mol a constante de Avogadro $\mathrm{N}_{A}$ [4].

Ao explorar o SI em sala de aula o professor deve estar afinado com a mudança do sistema de medidas para transpor aos alunos. $O$ professor precisa dominar 0 conhecimento didático relacionado ao conteúdo da disciplina, capacidade de abordá-lo de modo contextualizado, domínio de diferentes métodos e procedimentos de ensino e capacidade de escolhê-los conforme a natureza dos temas a serem tratados. $\mathrm{Na}$ educação é sugerido que [5]:

O fazer docente pressupõe a realização de um conjunto de operações didáticas coordenadas entre si. São o planejamento, a direção do ensino e da aprendizagem e a avaliação, cada uma delas desdobradas em tarefas ou funções didáticas, mas que convergem para a realização do ensino propriamente dito (LIBÂNEO 2004, p. 72).

\section{Materiais e Métodos}

O presente trabalho se estrutura na pesquisa-ação, por estreitar o diálogo entre as disciplinas na área de ciências da natureza, potencializando o ensino de ciências com objetivo de reforçar o aprendizado dos alunos e sensibilizá-los para as novas mudanças das unidades básicas do SI. A pesquisa foi efetivada nos meses de maio e junho de 2019, na Escola Estadual de Ensino Fundamental e Médio Professora Filomena Quitiba e teve o envolvimento de 10 turmas, sendo 2 turmas do primeiro ano, 5 turmas do segundo ano e 3 turmas do terceiro ano. Em cada turma houve a formação 7 grupos, cada um com uma das unidades do SI: comprimento, tempo, massa, corrente elétrica, 
temperatura termodinâmica, quantidade de matéria e intensidade luminosa. Os integrantes de cada grupo formado tiveram que realizar pesquisa na internet e consulta ao livro didático. Foi dado feedback pelos professores envolvidos durante a preparação dos trabalhos que foram apresentados em forma de seminários diante da turma.

\section{Resultados e Discussões}

O trabalhado realizado com os alunos foi relevante ao retratar o SI, ilustrado na Figura 3, que se baseia em sete grandezas físicas independentes, denominadas unidades de base.

Figura 3: Definições das unidades do SI

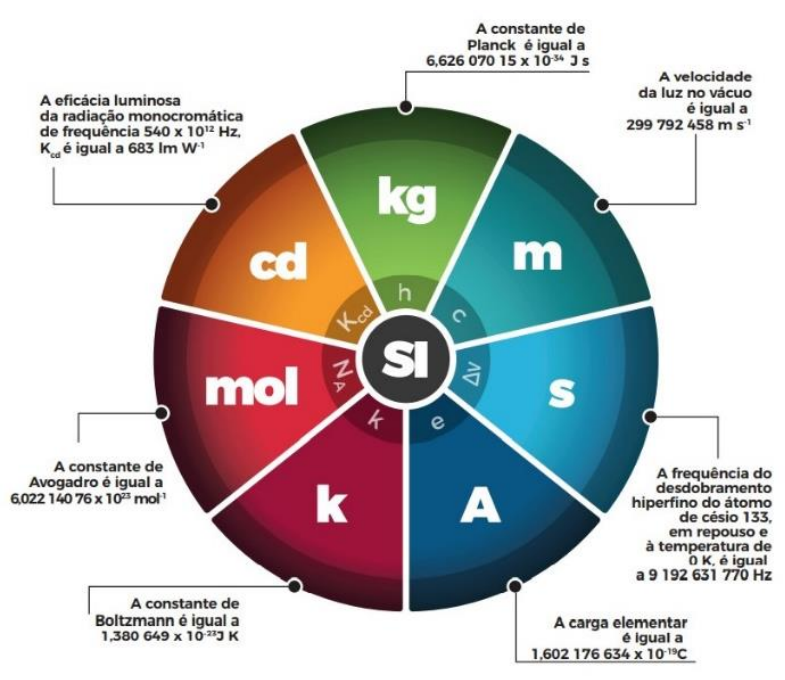

Fonte: Cartilha_O_novo_SI

A definição de unidade de massa por exemplo, perpassa por conteúdos de física moderna, o que justifica a necessidade de ser reforçada no ensino médio para a aprendizagem dos alunos. "A introdução da física moderna e contemporânea no ensino médio é de grande importância para a formação do estudante como futuro cidadão consciente do mundo tecnológico em que vive" [6]. No contexto do SI é fundamental e importante o entendimento da nova Física, como retrata no seguinte excerto [6]:

é imprescindível que o estudante do EM tenha conhecimento dos conceitos e fenômenos que constituem a tecnologia atual, uma vez que ela está presente em sua vida e, muito provavelmente, terá implicações em seu futuro profissional (LIMA, 2014, p. 73).

$\mathrm{Na}$ avaliação da atividade proposta, que foi pesquisa e culminância com seminários, adotamos critérios de participação dos integrantes do grupo e objetividade. Os alunos perceberam que o SI é um sistema coerente, com a combinação de unidades de base que produzem outras unidades, sem a necessidade de constantes. A proposta dos seminários fortaleceu o entendimento da importância do SI em vários contextos, além de ser uma obrigatoriedade legal, facilita a troca das informações, nas relações comerciais e científicas. O desafio é sensibilizar os professores em sua prática docente da relevância da reformulação, pois é um trabalho interdisciplinar. $\mathrm{Na}$ interação com os estudantes ficou perceptível que eles entenderam que o sistema de medidas é a língua avançada de toda ciência. Portanto, pode-se concluir que os objetivos propostos no trabalho docente, com os educandos, foram atendidos.

Diante do desafio de explanar este novo SI, com conceitos da física moderna, e com necessidade de abstração dos alunos, devemos relembrar as palavras "tornar as aulas desafiadoras e reflexivas, desenvolvendo o pensamento crítico dos alunos" [7]. Seminários, além da leitura de textos, podem representar uma estratégia em sala de aula como prática diversificada para maior compreensão do SI.

\section{Conclusão}

Os desafios do ensino dos conceitos contidos nas unidades do SI é tarefa que deve ser encarada anualmente em sala de aula, e, sua transposição requer o empenho docente. As tecnologias oriundas do conhecimento produzido, devido à física moderna, justificam a necessidade de reflexão dos educadores para levar os estudantes da educação básica a ficar em sintonia com o século XXI e almejar maior entendimento do conteúdo da física moderna. "O entendimento do mundo criado pelo homem atual, bem como a inserção consciente, participativa e modificadora do cidadão neste mesmo mundo define, por si só, a necessidade de debatermos e estabelecermos as formas de abordar tais conteúdos na escola" [8]. 


\section{Referências}

[1] HENNING, L. M. P. O pragmatismo em Lipman e sua influência na América Latina. Childhood \& Philosophy, Rio de Janeiro, v.1, n.2, p. 545-571, jul./dez. 2005.

[2] FREIRE, Paulo. Pedagogia da autonomia - Saberes necessários à prática educativa. São Paulo: Paz e Terra, 2011.

[3] INMETRO. Sistema Internacional de Unidades: SI. - Duque de Caxias, RJ: INMETRO/CICMA/SEPIN, 2012. 94 p. Traduzido de: Le Système international d'unités - The International System of Units 8. ed. 2006.

[4] Cartilha_O_novo_SI. Disponível em: http://metrologia.org.br/wpsite/wpcontent/uploads/2019/07/Cartilha O novo SI 29.06.202 9.pdf [SBF e SBM, 2019]. Acesso em: 12 Abri 2006.

[5] LIBÂNEO, J. C. Didática. São Paulo: Cortez, 2004.

[6] LIMA, Luis Gomes de. A abstração como ponte entre a física e a literatura na construção de conceitos de mecânica quântica no ensino médio (Dissertação de Mestrado) - Universidade de São Paulo - São Paulo, 2014.

[7] MATTHEWS, M. R. História, filosofia e ensino de ciências: a Tendência atual de reaproximação. Cad. Cat. Ens. Fís., v. 12, n. 3, p. 164-214, 1995. Disponível em: https://periodicos.ufsc.br/index.php/fisica/article/view/708 4. Acesso em: 08 Dezembro 2019.

[8] TERRAZZAN, E. A. A inserção da Física Moderna e Contemporânea no Ensino de Física na escola de $2^{\circ}$ grau. Caderno Catarinense de Ensino de Física, Florianópolis, v. 9, n. 3: p. 209-2014, dez. 1992 